\title{
Article \\ Piezoelectric Normally Open Microvalve with Multiple Valve Seat Trenches for Medical Applications
}

\author{
Claudia Patricia Durasiewicz ${ }^{1,2, *}$, Sophia Thekla Güntner ${ }^{1}\left(\mathbb{D}\right.$, Philipp Klaus Maier ${ }^{1}$, Wolfgang Hölzl ${ }^{2}$ \\ and Gabriele Schrag ${ }^{2}$ \\ 1 Fraunhofer EMFT Research Institution for Microsystems and Solid State Technologies, \\ 80686 Munich, Germany; sophia.guentner@st.oth-regensburg.de (S.T.G.); philippm1997@gmx.de (P.K.M.) \\ 2 Chair of Physics of Electrotechnology, Technical University of Munich, 80333 Munich, Germany; \\ wolfgang.hoelzl@tum.de (W.H.); schrag@tum.de (G.S.) \\ * Correspondence: claudia.patricia.durasiewicz@emft.fraunhofer.de; Tel.: +49-89-54759-497
}

check for updates

Citation: Durasiewicz, C.P.; Güntner, S.T.; Maier, P.K.; Hölzl, W.; Schrag, G. Piezoelectric Normally Open Microvalve with Multiple Valve Seat Trenches for Medical Applications. Appl. Sci. 2021, 11, 9252. https:// doi.org/10.3390/app11199252

Academic Editor: Eric Chappel

Received: 6 August 2021

Accepted: 30 September 2021

Published: 5 October 2021

Publisher's Note: MDPI stays neutral with regard to jurisdictional claims in published maps and institutional affiliations.

Copyright: (c) 2021 by the authors. Licensee MDPI, Basel, Switzerland. This article is an open access article distributed under the terms and conditions of the Creative Commons Attribution (CC BY) license (https:// creativecommons.org/licenses/by/ $4.0 /)$.

\begin{abstract}
Microfluidic systems for medical applications necessitate reliable, wide flow range, and low leakage microvalves for flow path control. High design complexity of microvalves increases the risk of possible malfunction. We present a normally open microvalve based on energy-efficient piezoelectric actuation for high closing forces and micromachined valve seat trenches for reliable valve operation. A comprehensive investigation of influencing parameters is performed by extensive fluidic 3D finite element simulation, derivation of an analytical closed state leakage rate model, as well as fabrication and test of the microvalve. Additional valve seat coating and a high force actuator are introduced for further leakage reduction. The microvalve has a wide-open flow range as well as good sealing abilities in closed state. Extensive fatigue tests of $1 \times 10^{6}$ actuation cycles show that additional coating of the valve seat or increased actuator strength promote sealing performance stability. Analytical calculations of leakage are suitable to estimate experimentally obtained leakage rates and, along with computational fluidic dynamic (CFD) simulations, enable future microvalve design optimization. In conclusion, we demonstrate that the presented normally open microvalve is suitable for the design of safe and reliable microfluidic devices for medical applications.
\end{abstract}

Keywords: microvalve; piezoelectric; microfluidics; modeling; FEA; CFD; fatigue

\section{Introduction}

Microfluidic systems for lab-on-chip applications, implantable or wearable medical devices often necessitate active flow path control that is achieved by using microvalves [1,2]. While passive microvalves show diode-like fluid path opening at forward pressure and closing at backwards pressure [3] or serve as constant flow regulators [4], active microvalves based on piezoelectric [5,6], shape memory alloy $[7,8]$, phase change $[9,10]$, or other actuation mechanisms [3] allow for opening and closing of fluid paths in an arbitrary, hence flexible and dedicated manner. External control of active microvalves enables functionalities like controlled dosing of drugs [11,12], mixture of reagents [10,13], confinement of a high pressure fluid to other volumes [14,15], as well as handling of small fluid volumes in medical devices and implants [16-20]. Such active flow path control can be achieved by piezoelectrically actuated microvalves, which are either of normally open (NO) or normally closed type, defined by their function in a non-actuated state [3], and typically consist of a piezoactuator, a valve diaphragm, and a valve seat [2]. Key figures of a high-performance microvalve are low leakage in closed state, a high flow rate in an open state, low power consumption, high particle contamination tolerance, and high stability of performance over lifetime. Additionally, medical applications like wearable drug dosing devices or implants require hermetic sealing of the device, low risk of component failure, as well as biocompatibility of all wetted surfaces [21]. 
Most recently, we reported on the development of an NO microvalve for microfluidic implants [14], showing low leakage rates $((10.9 \pm 28.1) \mu \mathrm{L} / \mathrm{min})$ as well as high flow rates in open state $((27.5 \pm 5.3) \mathrm{mL} / \mathrm{min})$ at a water pressure of $20 \mathrm{kPa}$. Insufficiently low manufacturing precision of the integrated O-ring sealing led to large sample-to-sample variations and induced various failure mechanisms of the microfluidic device. Constant closing due to flow-induced lift of the O-ring resulted in obstruction of the flow path and, hence, in partial or full blockage of the valve.

In this work, we suggest and investigate different alternative sealing concepts in order to overcome such problems. To this end, we design a novel, metal-based microvalve for liquid applications using biocompatible materials to meet requirements for medical applications. We omit movable sealing components, therefore reducing the risk of device failure, and investigate features like sophisticated geometric design, coating of the valve seat, or a high force actuator to further reduce leakage rates. A comprehensive analysis of parameters governing the performance provides insight into the microvalve's characteristics and allows for optimization and future design adaptation.

\section{Materials and Methods}

In order to investigate and optimize the presented piezoelectric $\mathrm{NO}$ valve concept, we manufacture various variants and evaluate them with a view to the resulting leakage rate, the open flow rate, and their performance stability. The fabrication process, the design variants as well as the methods to theoretically and experimentally evaluate their performance are described in this section.

\subsection{Microvalve Design, Operation, and Fabrication}

The design of the active diaphragm microvalve is depicted in Figure 1. It consists of a metal valve body (I) with an inlet (II) and an outlet (III), as well as a structured valve seat (IV). A metal diaphragm (V) is spanned over the valve seat with a piezoelectric ceramic layer (VI) bonded on top to create a bending actuator. In the initial state, the microvalve is normally open, as the diaphragm is bent in upward direction due to stresses imprinted by the manufacturing process described later. In non-actuated state, the NO microvalve allows for fluid flow from the inlet to the outlet. Using the inverse piezoelectric effect, the valve opens further when a negative electric field is applied. Under a positive electric field, closing of the valve is achieved when the actuator diaphragm is pressed tightly onto the valve seat. In this closed state, a low leakage rate of the microvalve is crucial for medical applications and can be drastically reduced by optimizing its sealing properties. To this end, we discuss impact parameters on sealing properties and introduce selected measures for low leakage in closed state: a concentric trench design, a high force actuator diaphragm, and additional coating on the valve seat.
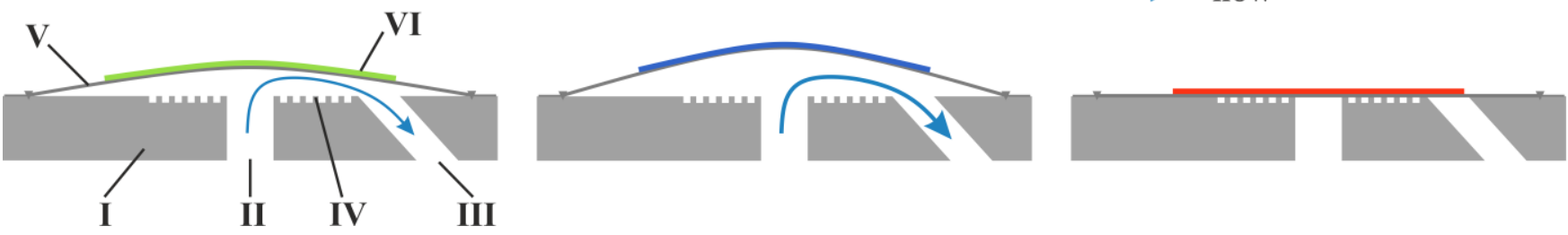

Figure 1. Working principle of the diaphragm-type piezoelectric NO valve. In non-actuated state, the valve is open and allows for fluid flow. By piezoelectric actuation, a negative electric field opens the valve further, resulting in reduced fluidic resistance, and a high positive field closes the fluid path by exerting a high contact pressure on the valve seat. 
In principle, tight sealing of a diaphragm-type microvalve is achieved by high contact pressure exerted by the actuator pressing the diaphragm onto a valve seat designed for low leakage. Therefore, both the piezoelectric bending actuator and the geometric design of the valve seat can be adapted to achieve optimal performance. Analogously to microvalves presented in research for low leakage gas applications [22-24], a valve seat design for low leakage can be realized by a concentric trench design (see Figure 2). In comparison to a flat valve seat, this design exhibits multiple beneficial effects towards leakage reduction. Firstly, a reduction in the contact area of the valve diaphragm and valve seat increases the contact pressure at the interface. A second effect results from increased surface friction of the fluid over the increased valve seat surface, eventually causing lower leakage flow. Finally, the fluid flowing over the valve seat exerts shear stress relative to the confined, resting fluid in the trenches, leading to a cascade of pressure losses across each trench.

a

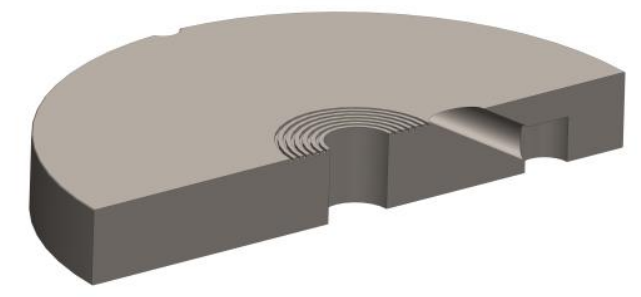

c

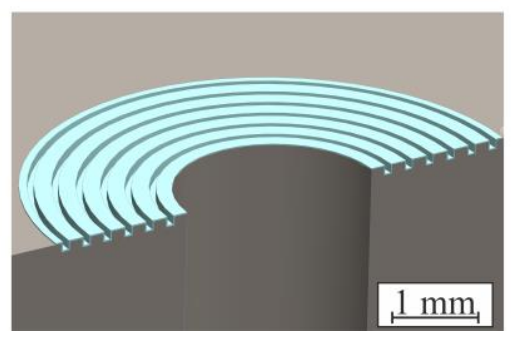

b

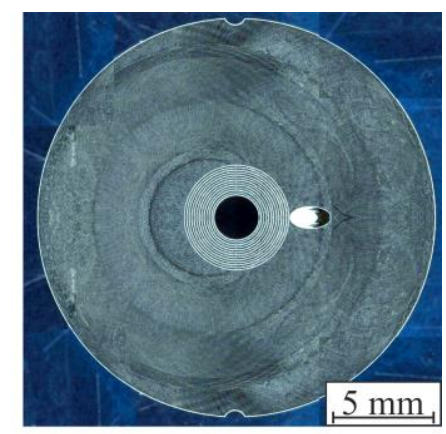

d

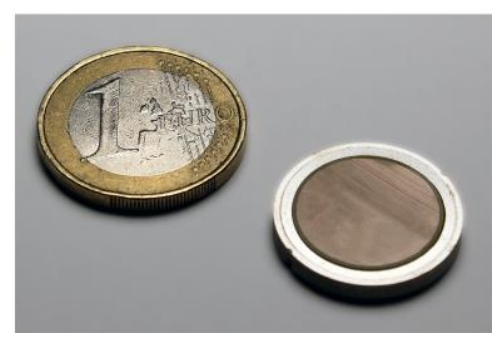

Figure 2. (a) Model of the NO valve body incorporating two fluid ports and micromachined trenches. (b) Light microscope picture of the micromachined valve steel body. (c) Model of the valve seat coated with Parylene-C. (d) Photograph of an assembled microvalve after laser welding and piezoelectric actuator bonding next to a Euro coin. The microvalve has a diameter of $20 \mathrm{~mm}$ and a height of $2.6 \mathrm{~mm}$.

To further enhance sealing, the contact pressure on the valve seat exerted by the valve diaphragm can be increased with a piezoelectric actuator that exhibits higher forces. For piezoelectric bulk material, this can be achieved by increasing the thickness of the actuator, resulting in a higher force when actuated by the same electric field.

Another method of modifying the leakage of two surfaces in contact is to use coatings to enhance their surface properties with a view to increased sealing behavior. A good candidate is Parylene- $C$, a chemically inert, biocompatible polymer with beneficial mechanical properties frequently used in medical applications [25]. As the Young's modulus of Parylene-C is two orders of magnitude smaller than the Young's modulus of steel [26,27], the polymer's elasticity can be used to create a tight sealing in microvalves [22].

In order to evaluate the potential of each of the mentioned design measures and their impact on the performance of the microvalve, we design and manufacture them in different variants with respect to geometrical dimensions, structuring of the valve seat, and additional coating.

Figure 2a shows the basic design of the presented NO microvalve. A rigid metal body comprises two fluid ports and concentric trenches, creating the valve seat-both the width and depth of each trench amount to $100 \mu \mathrm{m}$. The diameter of the innermost trench is $2.5 \mathrm{~mm}$, and all 6 trenches are evenly spaced concentrically with a distance of $150 \mu \mathrm{m}$ from 
each other. The NO microvalve is manufactured from stainless steel, which offers high resistance to plastic deformation, high machinability, and biocompatible properties [28].

Structuring of the baseplate (see Figure $2 b$ ), including valve seat trenches, is achieved by high precision milling (Kern Evo, Kern Microtechnik $\mathrm{GmbH}$ ), resulting in valve seat trench depths of $(101.8 \pm 3) \mu \mathrm{m}$. A metal actuator foil, etched from a cold-rolled stainless steel sheet material, is joined to the valve body by laser welding using a fiber laser $(1070 \mathrm{~nm}$ wavelength ytterbium fiber laser YLR-1000 SM, IPG Laser GmbH). We ensure hermetic sealing of the valve chamber and high strength of the weld seam by firm clamping of the foil onto the baseplate and an overflow of the welding area with shielding gas (Argon 4.6) at room temperature. During laser welding, the actuator foil experiences a temperature gradient from the welding fusion zone to zones not affected by heat, and after the molten steel solidifies, residual stresses remain in the actuator foil. These residual stresses ultimately result in an initial deflection of the actuator foil in an upwards direction and establish the NO state of the microvalve. After laser welding, the piezoelectric bending actuator is created by gluing a lead zirconate titanate (PZT) disc actuator onto the metal actuator diaphragm using a two-component epoxy glue (EPO-TEK 353ND).

We investigate three variants of the microvalve with micromachined trenches. A basic design comprises a $0.1 \mathrm{~mm}$ thick steel diaphragm as well as a $0.2 \mathrm{~mm}$ thick PZT actuator and is fabricated in a quantity of 10 . In the coated design, the effect of a $15 \mu \mathrm{m}$ Parylene-C coating on the valve seat (see Figure 2c) is investigated with another 10 manufactured valves with the same bending actuator as the basic design. In a third high force design, 5 microvalves without coating on the valve seat are fabricated with a $0.15 \mathrm{~mm}$ thick steel diaphragm and a $0.3 \mathrm{~mm}$ thick PZT actuator in order to increase the contact pressure exerted to the valve seat by the actuator. Table 1 provides an overview of all three manufactured design variants of the NO microvalve.

Table 1. Overview on fabricated NO microvalve variants.

\begin{tabular}{ccccc}
\hline $\begin{array}{c}\text { Microvalve Design } \\
\text { Variant }\end{array}$ & $\begin{array}{c}\text { Number of } \\
\text { Fabricated Valves }\end{array}$ & Valve Seat Coating & $\begin{array}{c}\text { Piezoceramic } \\
\text { Thickness }\end{array}$ & $\begin{array}{c}\text { Metal Diaphragm } \\
\text { Thickness }\end{array}$ \\
\hline Basic design & $n=10$ & No coating & $0.2 \mathrm{~mm}$ & $0.1 \mathrm{~mm}$ \\
Coated design & $n=10$ & Parylene-C coating & $0.2 \mathrm{~mm}$ & $0.1 \mathrm{~mm}$ \\
High force design & $n=5$ & No coating & $0.3 \mathrm{~mm}$ & $0.15 \mathrm{~mm}$ \\
\hline
\end{tabular}

For realizing the coating of the valve seat, we use chemical vapor deposition of Parylene-C. To this end, the steel bodies are masked using a structured semiconductor wafer processing tape (Nitto SWT 10+R), limiting the coated surface to the trench area of the microvalve. Coating via Gorham route [29] is achieved in a plasma coating system (Plasma Parylene LC 300 RW, Plasma Parylene Systems GmbH). Under vacuum conditions, the substrates are pretreated with Silane A-174 for in-situ silanization from the gas phase at room temperature. Subsequently, $25 \mathrm{~g}$ of Parylene- $\mathrm{C}$ dimer is sublimed at $130{ }^{\circ} \mathrm{C}$ followed by pyrolysis into reactive monomers at $740^{\circ} \mathrm{C}$, and final polymerization takes place in the coating chamber at room temperature. A coating process duration of approximately $4 \mathrm{~h}$ results in a (15 \pm 2.5$) \mu \mathrm{m}$ thickness of the coating layer. Removal of the mask is enabled by laser ablation using an infrared $\mathrm{CO}_{2}$ laser $(10.6 \mu \mathrm{m}$ wavelength Speedy 360, TROTEC Laser $\mathrm{GmbH}$ ), since mechanical stripping alone causes delamination of the coating. Finally, we proceed with the preparation of the coated steel bodies equivalently to the uncoated valves: we attach the steel actuator foil to the valve body by laser welding, followed by glue bonding of the PZT on top of the diaphragm (Figure 2d).

\subsection{Parameter Studies of Valve Seat Design Using FEA}

In order to investigate the impact of the geometrical dimensions of the circular trenches on the fluidic resistance of the valve seat and, hence, on the potential improvement with respect to its fluidic performance, we perform a finite element analysis (FEA). To this end, 
we compare the fluid flow through an axisymmetric, annular channel with concentric trenches to the flow between two unstructured flat and parallel discs. The used simulation model is shown in Figure 3 and neglects the inlet and outlet tubes. Instead, we assume a radially symmetric outflow in the direction of the trench cavities leaving along the outer rim of the annular channel, which resembles the valve chamber. As an additional simplification, we assume a constant height along the channel. These assumptions overestimate the total flow rate compared to the real geometry. However, as we are interested in the relative changes of the fluidic resistance due to geometrical changes in the trench geometries and compared to the trenchless disc geometry, this is deemed as an acceptable error.

$\mathbf{a}$

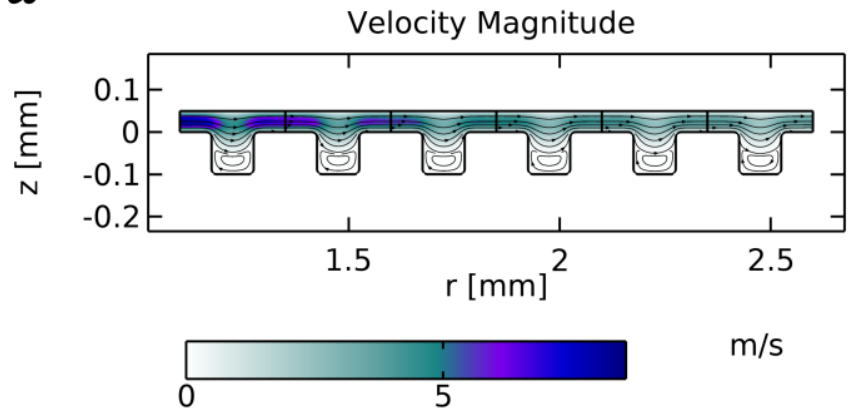

b

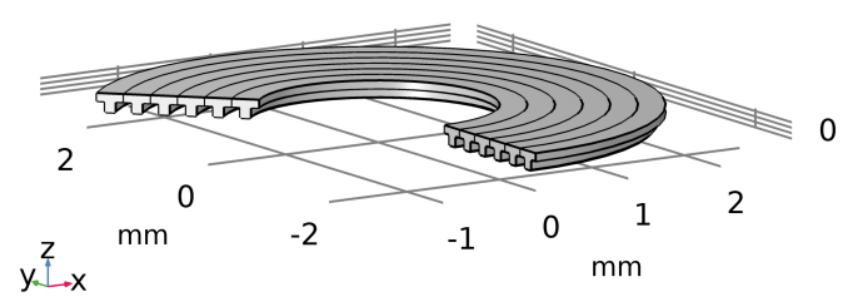

Figure 3. Simulation model used to evaluate the impact of concentric, ring-shaped trenches on the fluidic resistance of the valve seat. (a) Cross-sectional view of the two-dimensional simulation domain. (b) Section of the axisymmetric model. The arrows visualize the fluid flow from the inner to the outer boundary, as well as the vortices developing in the trench.

Figure 3a shows the two-dimensional simulation domain, which represents the crosssection of the partially depicted axisymmetric model of the right part of Figure $3 \mathrm{~b}$. The inlet is located at $x=0$. The boundary at $x=2.7 \mathrm{~mm}$ is an open boundary. All other boundaries are defined as walls with a no-slip condition. For the inflow, the velocity field is specified to be fully developed at an average pressure level of $20 \mathrm{kPa}$, and we solve for a stationary and laminar flow of water at room temperature.

To study the different effects of the geometry on the fluidic resistance of this arrangement when the microvalve is open, we vary the height of the valve chamber, as well as the height and width of the concentric trenches, and determine the fluidic resistance, which is calculated as the ratio of the pressure drop $\Delta p$ and the flow rate $\dot{q}$. We use the resistance of two parallel discs as a reference in order to evaluate and quantify the relative changes due to the geometric variation of the valve seat trenches. This resistance is calculated analytically to:

$$
\frac{\Delta p}{\dot{q}}=\frac{6 \mu}{\pi h^{3}} \ln \frac{r_{1}}{r_{0}},
$$

where $r_{0}$ is the inner radius, $r_{1}$ the outer radius, $h$ the height of the valve chamber, and $\mu$ the viscosity of the fluid. A detailed derivation of this formula is given in Appendix A. The formula is valid for small Reynold's numbers and Newtonian fluids and does not account for the trench geometry. The reason for the latter is that the presence of trenches leads to the formation of vortices, whose size and vorticity depend non-linearly on the surrounding conditions such as the fluid velocities above and below these vortices, the wall distances, as well as the viscosity of the fluid. As the incorporation of these dependencies is challenging, we deem a comparison between a trench geometry and two parallel discs to be sufficient to evaluate the effects caused by the trenches.

The FEA is carried out with the software package COMSOL Multiphysics. In addition to the above-mentioned approximations, we replace the right angles at the trenches with small circular arcs. This is motivated by a better convergence behavior and a smaller numerical error due to the smoother boundary and, additionally, reflects the real micromachined 
structure much better than a sharp right angle. In order to avoid significant changes in the results by introducing these radii, they are kept small enough.

Our FEA does not include the analysis of fluidic leakage of the microvalve in closed state. The leakage flow is caused by the imperfect contact between the diaphragm and the valve seat, which in turn is a result of the surface roughness of the solid bodies, as well as plastic deformations due to thermal stresses caused by laser welding. These specific values cannot be readily incorporated into an FEA. Moreover, when the diaphragm establishes or loses contact with the valve body, the topology of the fluidic domain between them changes, leading to node definition errors. A typical remedy to this problem is to introduce a small non-vanishing fluid domain between the diaphragm and the valve. As this adds artificial leakage to the overall results, such an approach would defeat the attempt to attain deeper and more sophisticated insights into the real fluidic leakage. Instead, we derive an analytical model to calculate the leakage rate in closed state, which is presented in the following section.

\subsection{Analytical Modeling of Leakage Rates}

In this section, an analytical model for the estimation of the leakage rates of the NO valves in closed state is presented. Leakage is the result of imperfect contact between the steel foil and the steel valve body due to surface roughness. In order to evaluate the leakage flow, we first determine the average separation between the steel diaphragm and the valve seat. This separation represents the height of the microchannel, determining the pressure-dependent flow rate. In order to solve this problem, we apply the approach of Persson [30], who studied the contact problem of two solids with surface roughness squeezed against each other. This leads to the average separation $u\left(p_{\text {contact }}\right)$ between the steel diaphragm and the valve body as a function of the contact pressure $p_{\text {contact }}$ :

$$
u\left(p_{\text {contact }}\right)=\gamma \alpha^{-1} h_{r m s} \log \left(\beta \epsilon q_{0} h_{r m s} \frac{E^{*}}{p_{\text {contact }}}\right)
$$

where the constant $\gamma$ is set to one, which means assuming perfectly elastic deformation, $\alpha$ and $\beta$ are surface roughness constants, $h_{r m s}$ is the root mean square of the surface roughness, $\epsilon$ is a constant related to the power spectrum of the surface roughness $C(q)$ and the lower and upper cutoff wave vectors $q_{0}$ and $q_{1}$ of the surface, and $\mathrm{E}^{*}$ the plane-strain modulus. The contact pressure $p_{\text {contact }}$ of the two bodies is equivalent to the maximum force exerted by the actuator diaphragm. The so-called blocking pressure $p_{\text {block }}$ of the actuator is scaled by the ratio of valve diaphragm surface to the contact area to achieve the contact pressure and can be calculated according to [31]:

$$
p_{\text {contact }}=\frac{A_{\text {diaphragm }}}{A_{\text {contact }}} p_{\text {block }}
$$

Comprehensive derivations of Equations (2) and (3) are provided in Appendix B.

Applying Equation (2), we are now able to calculate the leakage flow rate depending on the pressure drop over the closed valve. To this end, an appropriate flow model of the leakage flow of water through microscale channels and openings must be developed. Since water can be considered as an incompressible fluid [32] and the Reynolds number is (as in almost all microfluidic applications) much smaller than 1 [33], the flow is modeled as a simple laminar Poiseuille flow driven by the pressure difference $\Delta p$ between the inlet and the outlet of the valve. The channel geometry is determined by the design of the sealing and the average surface separation due to surface roughness. The average separation height is on the order of some micrometers, whereas the sealing dimensions are 2-3 orders of magnitude higher. Therefore, the leakage channel is assumed to be a rectangular slit, whose width $w$ is much larger than its height $h=u(p)$, so that the side walls of the channel can be neglected, and the geometry can be regarded as a channel between two infinite 
plates [34]. Applying no-slip boundary conditions $v(z=0)=v(z=h)=0$, the velocity profile and resulting flow rate are given by:

$$
\begin{gathered}
v_{x}(z)=\frac{\Delta p}{2 \mu L}((h-z) z), \\
Q=\int_{0}^{w} d y \int_{0}^{h} d z v_{x}=\frac{h^{3} w}{12 \mu} \frac{\Delta p}{L},
\end{gathered}
$$

where $\mu$ is the viscosity of water.

The above-described geometrical simplification leads to a worst-case scenario estimation of the leakage rate; therefore, it is expected that the analytical model overestimates the observable leakage rate and constitutes an upper limit for the evaluation of the manufacturing-induced imperfections of the valve and the hereof resulting potential issues in its reliability in the medical application.

\subsection{Experimental Characterization}

The mechanical and fluidic characteristics of the NO valve are extensively tested in order to assess its performance and to estimate its reliability in the field. Additionally, the measurements are used to extract parameters necessary for model calibration, theoretical design studies, and analytical calculations of the leakage rates.

The operation of the diaphragm microvalve is fundamentally defined by the piezoelectrically driven diaphragm movement. Free actuator movement is allowed in open state of the microvalve, whereas further actuator movement is restricted when the actuator sits down on the valve seat in closed state. The mechanical stroke of the actuator diaphragm is measured optically using a white light profilometer (Fries Research and Technology; sensor range of $3 \mathrm{~mm}$, maximal resolution of $30 \mathrm{~nm}$ ) with a quasi-static voltage actuation (amplifier SVR 500-3, piezosystem jena GmbH) ranging from $-0.4 \mathrm{kV} / \mathrm{mm}$ to $2.0 \mathrm{kV} / \mathrm{mm}$ to detect field-dependent open and closed state. Repetitive measurements using this setup reveal a measurement accuracy of the total actuator stroke of $2 \mu \mathrm{m}$. Additionally, the profilometer is used for surface inspection of the microvalve steel diaphragms in order to determine the fractal dimension as well as the maximum and minimum wave vectors $q_{0}$ and $q_{1}$ of the surface, respectively, serving as input parameters for analytical leakage modeling (see Section 2.3).

Subsequently, all manufactured valves are characterized with a view to the fluidic performance using deionized water at room temperature. The instruments used for these investigations are Coriflow sensors of different ranges (Bronkhorst MINI CORI-FLOW M14: range $0.5 \mathrm{~mL} / \mathrm{min}$ to $167 \mathrm{~mL} / \mathrm{min}$, accuracy: $\pm 0.2 \%$ and ML120V00: range $0.8 \mu \mathrm{L} / \mathrm{min}$ to $500 \mu \mathrm{L} / \mathrm{min}$, accuracy: $\pm 0.2 \%$ ) as well as a pressure controller (Mensor CPC 3000 ; range $-50 \mathrm{kPa}$ to $200 \mathrm{kPa}$, accuracy: $\pm 50 \mathrm{~Pa})$.

Applying this measurement setup, the assembled microvalves undergo different fluidic tests. As an initial characterization, we measure their pressure-dependent NO flow rate, their quasi-static opening and closing flow characteristics, and the closed state leakage rate. NO flow rates are evaluated without electrical actuation of the piezoceramic and increasing water pressure at the inlet of the microvalve up to $100 \mathrm{kPa}$. Quasi-static opening and closing characterization of the microvalve at an inlet pressure of $20 \mathrm{kPa}$ is achieved by sinusoidal actuation of the piezoceramic at a frequency of $\mathrm{f}=0.01 \mathrm{~Hz}$ and electric fields between $-0.4 \mathrm{kV} / \mathrm{mm}$ and $2.0 \mathrm{kV} / \mathrm{mm}$. For evaluations of the pressure-dependent leakage rate, the valve's inlet pressure is increased from $0 \mathrm{kPa}$ to $20 \mathrm{kPa}$, while the piezoceramic is subjected to a constant electric field of $2.0 \mathrm{kV} / \mathrm{mm}$.

Finally, a fatigue test of the microvalves is performed with 5 microvalves of each design variant. The valves are operated at a constant fluidic pressure load of $20 \mathrm{kPa}$, a sinusoidal electric signal of $100 \mathrm{~Hz}$, and an electric field of $-0.4 \mathrm{kV} / \mathrm{mm}$ to $2.0 \mathrm{kV} / \mathrm{mm}$ for $1 \times 10^{6}$ actuation cycles. After this long-term excitation, the above-described fluidic 
characterization methods are repeated in order to evaluate the fatigue of the microvalves, e.g., in terms of increased leakage rates or piezoceramic material failure.

\section{Results and Discussion}

The variants of the NO microvalve without additional and moving sealing components listed in Table 1 are designed, manufactured, and investigated applying the methods described in Section 2. At first, the optimal geometric dimensions of the microstructured valve seat are investigated in an FEA parameter study in order to estimate the impact of the concentric trenches on the fluidic resistance and, hence, on the open state flow rates. Applying the analytical model of Section 2.3., the pressure-dependent leakage rates of the different valve geometries are calculated and compared to measurements, and finally, the performance and long-term operation of all variants are evaluated experimentally.

\subsection{Parameter Study: Impact of Microstructured Valve Seat}

The impact of the trenches on the flow field is an essential element of the working principle of the NO microvalve. We perform a detailed FEA parameter study in order to evaluate the fluidic resistance of the valve comprising the valve seat trenches for varying channel height, trench width, and trench depth. Figure 4 provides an overview of the dependencies of the fluidic resistance on the varied geometric parameters.

a

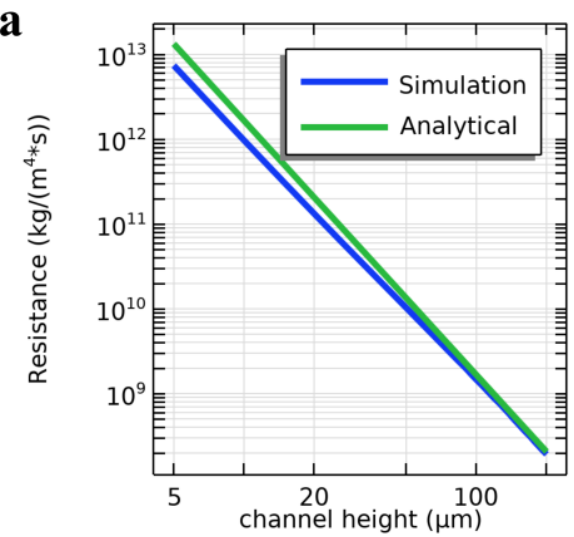

b

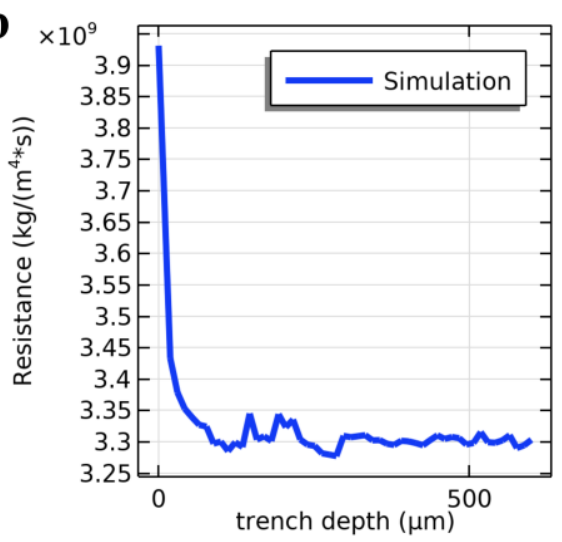

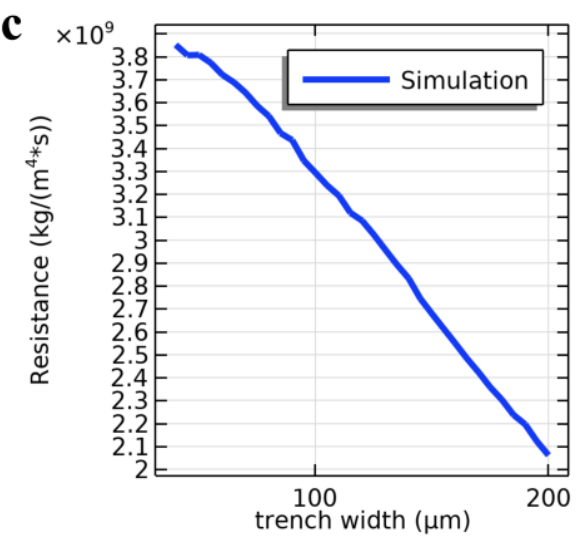

Figure 4. (a) Fluidic resistance as a function of the height of the channel above the trenches. (b) Fluidic resistance depending on the depth of the trenches; the analytically calculated resistance at zero depth amounts to $3.9 \times 10^{9} \mathrm{~kg} / \mathrm{m}^{4} \mathrm{~s}$. (c) Fluidic resistance for varying width of the trenches. Again, the resistance at zero width amounts to $3.9 \times 10^{9} \mathrm{~kg} / \mathrm{m}^{4} \mathrm{~s}$.

The dependency of the fluidic resistance on the channel height is presented in Figure $4 \mathrm{a}$, which we obtain by varying the channel height from $5 \mu \mathrm{m}$ to $200 \mu \mathrm{m}$, while other geometric parameters are set to the corresponding values of the manufactured design. For larger channel heights, the resistance converges against the analytically calculated resistance given in Equation (1). As shown in Figure 5, vortices develop inside the trenches, but their impact on the fluidic resistance becomes less relevant as the channel height increases.

The channel height itself is not a static design parameter of the valve but ultimately varies with the actuation of the piezoceramic actuator as well as with the inlet pressure depending on the elastic constants of the actuator diaphragm; hence, the simulations provide insight into the influences of the trenches in the microvalve's open state. The results indicate that this sealing concept is suitable for functional open state flow through the valve, as this trench design does not impede open state flow by an eventually increased fluidic resistance. 
a

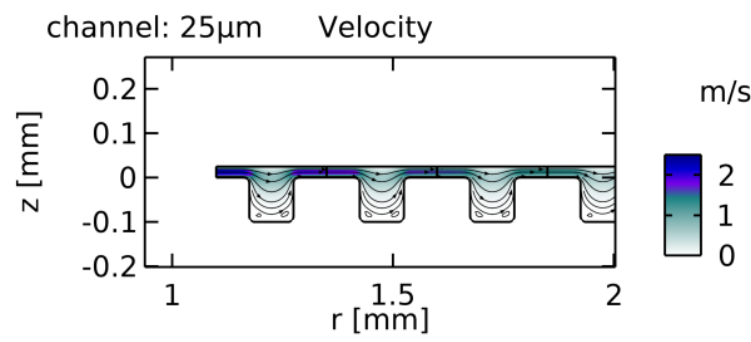

b

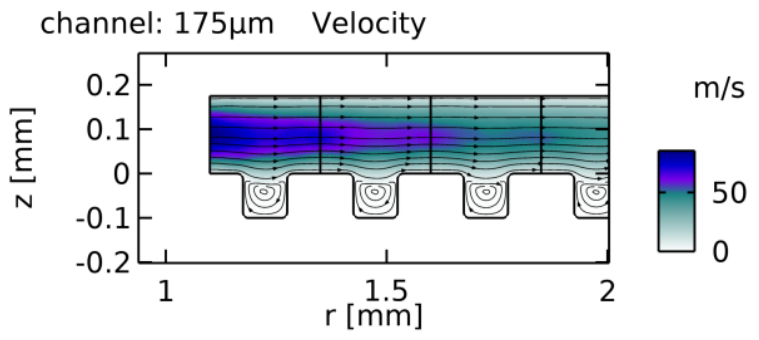

Figure 5. (a) Velocity field of the flow for a channel height of $25 \mu \mathrm{m}$. (b) Velocity field of the flow for a channel height of $175 \mu \mathrm{m}$. Vortices develop inside the trenches, having impact on the fluidic resistance; however, this impact decreases with increasing channel height.

Figure $4 \mathrm{~b}$ shows the dependency of the fluidic resistance on the depth of the trenches at a channel height of $75 \mu \mathrm{m}$. The width of the individual trench is $100 \mu \mathrm{m}$. It reveals that the width of $100 \mu \mathrm{m}$ limits the size of the arising vortices contributing to the resistance. Figure 6a shows the typical flow for shallow trenches with a larger width than depth. In this case, small vortices arise only in the trench corners, and the flow is mostly uniform. Increasing the depth, the fluidic resistance decreases until a depth of the trenches of about $150 \mu \mathrm{m}$ (c.f. Figure 4b). For this specific trench geometry, the first vortices are now fully developed. Increasing the depth even further leads to more vortices; however, these also affect each other and exert a shear-stress-based resistance towards the neighboring vortices, as can be seen in Figure $6 \mathrm{~b}$. The vortices become weaker the deeper they are located in the trench. Due to this, the resistance does not change much for larger trench depths and saturates at an about $20 \%$ lower value than the analytically calculated value for a channel between two parallel discs without trenches.

$\mathbf{a}$

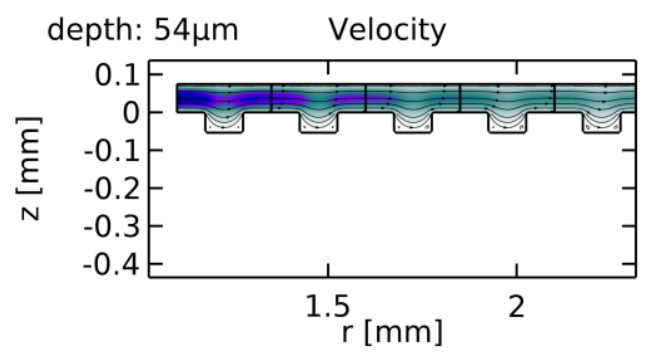

b

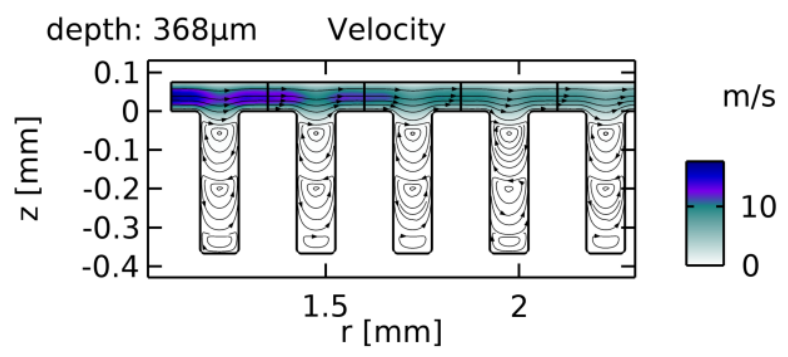

Figure 6. (a) Flow field for a trench depth of $54 \mu \mathrm{m}$. (b) Flow field for a trench depth of $368 \mu \mathrm{m}$. Several induced vortices interact with each other, causing shear stress towards themselves, rendering deeper vortices irrelevant for the main leakage flow. The diameter of the vortices depends on the width of the trenches, which here amounts to $100 \mu \mathrm{m}$.

The oscillating behavior of the fluidic resistance in Figure $4 \mathrm{~b}$ can be explained by the discrete nature of the vortices, as fractional vortices cannot exist. In the beginning, the resistance becomes smaller with deeper trenches, as the fluid experiences less friction with the walls and is less confined. Once the depth reaches the same value as the trench width, the first vortex is formed, causing an increase in resistance. Increasing the depth further leads to a smaller resistance at first until the next vortex establishes. However, the more vortices are created inside the trench, the less they contribute to the overall resistance, as they interact more and more with each other than with the main flow field.

Finally, the effect of the trench width on the fluidic resistance is depicted in Figure 4c. The resistance decreases with the increasing width of the trenches as the individual fluid domains in those trenches become less restricted by the trench walls, ultimately leading to lower pressure losses due to the exerted shear stress. Figure 7a shows the flow field for a trench width of $100 \mu \mathrm{m}$ and Figure $7 \mathrm{~b}$ for $180 \mu \mathrm{m}$ wide trenches and a trench depth of 
$100 \mu \mathrm{m}$. Only very small vortices arise in the corners with a negligible contribution to the fluidic resistance. The results suggest that for a smaller width of the individual trenches, the formation of large vortices causes higher fluidic resistance of the valve.

a

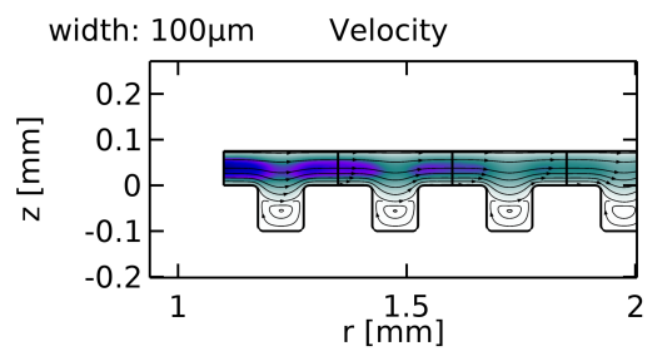

b

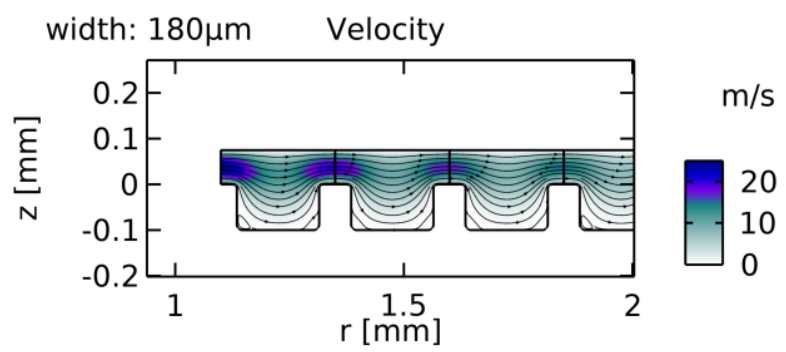

Figure 7. (a) Flow field for a width of the trenches of $100 \mu \mathrm{m}$. (b) Flow field for a width of the trenches of $180 \mu \mathrm{m}$, where no vortex generation is observed.

In conclusion, the FEA parameter study of the channel regions with integrated trenches of different geometrical dimensions shows a distinct and systematic impact on the fluidic resistance and, hence, on the open state flow behavior of the microvalves. The so-obtained deep understanding of their influence by flow-induced vortex generation enables to optimally design trenches with respect to width and depth of the individual trenches in order to create an appropriate flow resistance.

\subsection{Modeling of Leakage Rate}

Figure 8 depicts the pressure-dependent leakage rates in closed state of the introduced microvalve designs based on the analytical leakage model derived in Section 2.3. The depicted standard deviation is a result of the calculated propagation of manufacturing tolerances and uncertainties in material properties.

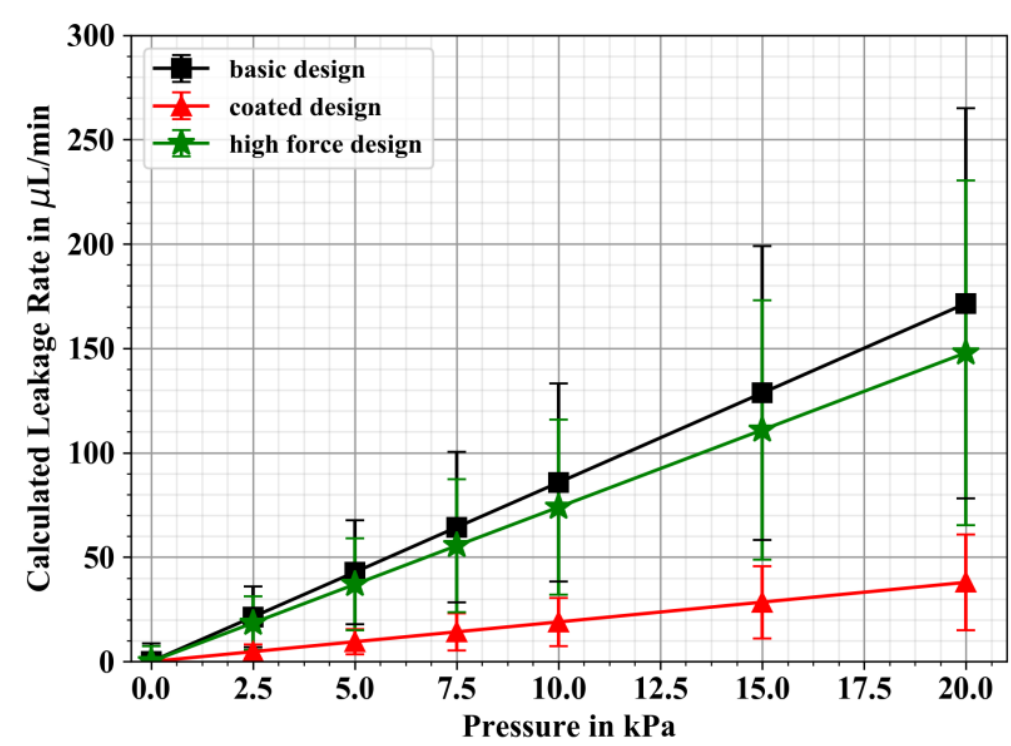

Figure 8. Analytically modelled pressure-dependent leakage rates for the three microvalve variants. Error bars show standard deviations based on calculated propagation of uncertainty of manufacturing and material tolerances.

The analytically calculated leakage rates show a clear linear dependency on the inlet pressure. The highest leakage of $(171.5 \pm 93.4) \mu \mathrm{L} / \mathrm{min}$ at $20 \mathrm{kPa}$ is expected for the basic design. The high force design shows no significant change in leakage, where increased contact pressure of the valve diaphragm results only in a slightly reduced leakage of 
$(147.9 \pm 82.6) \mu \mathrm{L} / \mathrm{min}$ at the same fluidic pressure applied. All microvalve design variants exhibit large standard deviations of about $60 \%$ due to high manufacturing tolerances of the steel actuator foils, propagating to high relative uncertainty in the calculated leakage rates. Coated microvalves show significantly reduced absolute values of leakage rates. The effective Young's modulus resulting from the Parylene-C-steel interface leads to a lower value of the average surface separation (see Equation (2)) and, consequently, leakage is expected to be as low as $(37.9 \pm 23) \mu \mathrm{L} / \mathrm{min}$ for an inlet pressure of $20 \mathrm{kPa}$, and, hence, is much lower than for the two other design variants. The theoretically determined leakage rates are compared to measured values of fabricated microvalves of the three designs; results are presented in Section 3.3.

\subsection{Experimental Characterization}

We investigate the characteristics and fluidic performance of the presented $\mathrm{NO}$ valve design variants (see Table 1). Out of the 5 manufactured high force design microvalves, one is excluded from the study due to insufficient glue bonding of the piezoceramic. The experimentally obtained actuator stroke, the open flow rates, and the results of the leakage measurements of all 24 tested microvalves are summarized in Table 2. Additionally, the calculated leakage rates based on the derived analytical models are provided for comparison.

Table 2. Overview of the experimental results for the three studied design variants of the NO microvalve.

\begin{tabular}{|c|c|c|c|c|c|c|}
\hline $\begin{array}{c}\text { Microvalve } \\
\text { Design Variant }\end{array}$ & $\begin{array}{l}\text { Tested } \\
\text { Valves }\end{array}$ & $\begin{array}{l}\text { Actuator } \\
\text { Stroke, } \\
\text { in } \mu \mathrm{m}\end{array}$ & $\begin{array}{c}\text { Max. Open Flow } \\
\text { at } 20 \mathrm{kPa}, \\
\text { in } \mathrm{mL} / \mathrm{min}\end{array}$ & $\begin{array}{l}\text { NO Flow at } \\
100 \mathrm{kPa} \text {, in } \\
\mathrm{mL} / \mathrm{min}\end{array}$ & $\begin{array}{c}\text { Measured } \\
\text { Leakage at } \\
20 \mathrm{kPa} \text {, in } \\
\mu \mathrm{L} / \mathrm{min}\end{array}$ & $\begin{array}{c}\text { Calculated } \\
\text { Leakage at } \\
20 \mathrm{kPa} \text {, in } \\
\mu \mathrm{L} / \mathrm{min}\end{array}$ \\
\hline Basic design & 10 & $56.4 \pm 4.7$ & $30.1 \pm 3.4$ & $122 \pm 9$ & $24.8 \pm 9.6$ & $171.5 \pm 93.4$ \\
\hline Coated design & 10 & $51.6 \pm 6.7$ & $29.7 \pm 4.5$ & $119.1 \pm 8.4$ & $25.1 \pm 7.9$ & $37.9 \pm 23$ \\
\hline High force design & 4 & $55.9 \pm 2.6$ & $24.9 \pm 1.8$ & $83.6 \pm 4.8$ & $19.8 \pm 4.9$ & $147.9 \pm 82.6$ \\
\hline
\end{tabular}

Figure 9a depicts an exemplary measurement of the microvalve actuator stroke. The change in slope at approximately $1 \mathrm{kV} / \mathrm{mm}$ shows the actuator touch down on the valve seat. For electric fields $<1 \mathrm{kV} / \mathrm{mm}$, open state actuator movement of more than $50 \mu \mathrm{m}$ in total is achieved, and the occurrence of piezoelectric hysteresis becomes apparent. Closed state starts at electric fields beyond $1 \mathrm{kV} / \mathrm{mm}$, where further downwards displacement is blocked, and the contact pressure of the valve diaphragm and the valve seat increases. Comparison of the three variants of the microvalve design reveals no significant difference in total actuator stroke (Table 2). The slight difference in the stroke of the coated microvalves could be explained by the reduced distance of the valve diaphragm to the valve seat by the added coating.

Figure $9 \mathrm{~b}$ shows an exemplary measurement of the field-dependent flow rates with discernible open and closed states. Due to the influence of piezoelectric hysteresis of the actuator, closed state of the microvalve is achieved at approximately $1.6 \mathrm{kV} / \mathrm{mm}$ for increasing fields, whereas for decreasing fields, the microvalve remains closed until a field of approximately $0.6 \mathrm{kV} / \mathrm{mm}$. Active opening of the valve is facilitated by further upwards movement of the diaphragm at negative fields, where maximal open flow rates are achieved. For microvalves with a $0.2 \mathrm{~mm}$ thick piezoelectric actuator, similar maximal open flow rates of $(30.1 \pm 3.4) \mathrm{mL} / \mathrm{min}$ (basic design) and $(29.7 \pm 4.5) \mathrm{mL} / \mathrm{min}$ (coated design) are measured. In contrast, the microvalves with a $0.3 \mathrm{~mm}$ thick piezoactuator show lower maximal open flow rates of $(24.9 \pm 1.8) \mathrm{mL} / \mathrm{min}$, most likely due to increased stiffness of the valve diaphragm: The fluidic pressure acting on the valve diaphragm displaces it further upwards for the less stiff actuators with a $0.2 \mathrm{~mm}$ thick piezoceramic, enabling even higher flow rates due to the increased height of the valve chamber. The increased stiffness of the valve diaphragm for $0.3 \mathrm{~mm}$ piezoactuator valves impedes additional displacement of the diaphragm induced by fluid pressure, resulting in a lower maximum open flow. 
$\mathbf{a}$

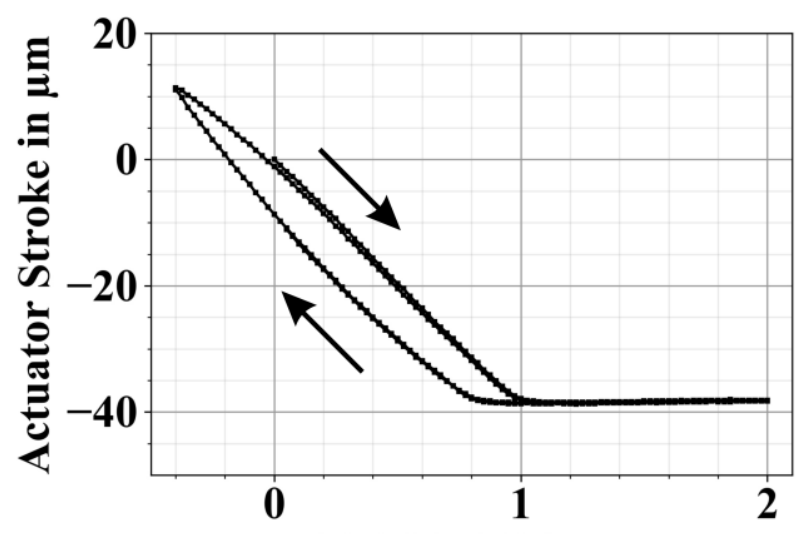

c

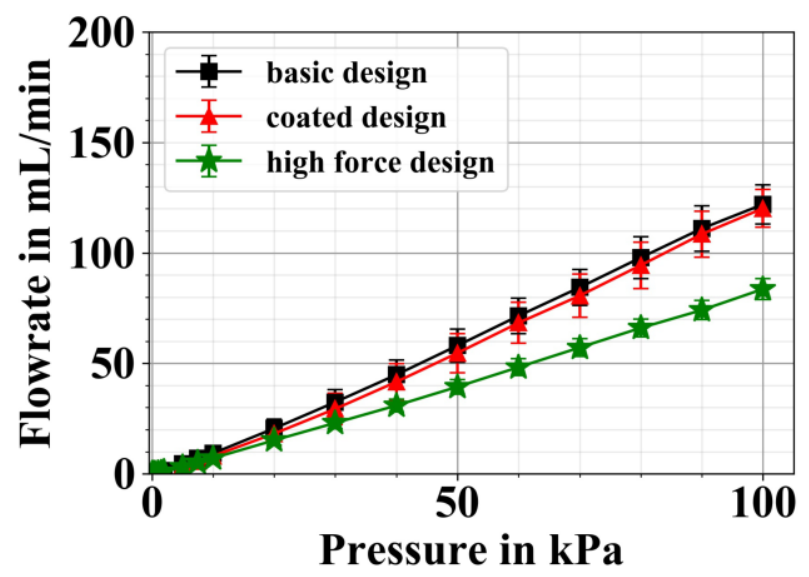

b

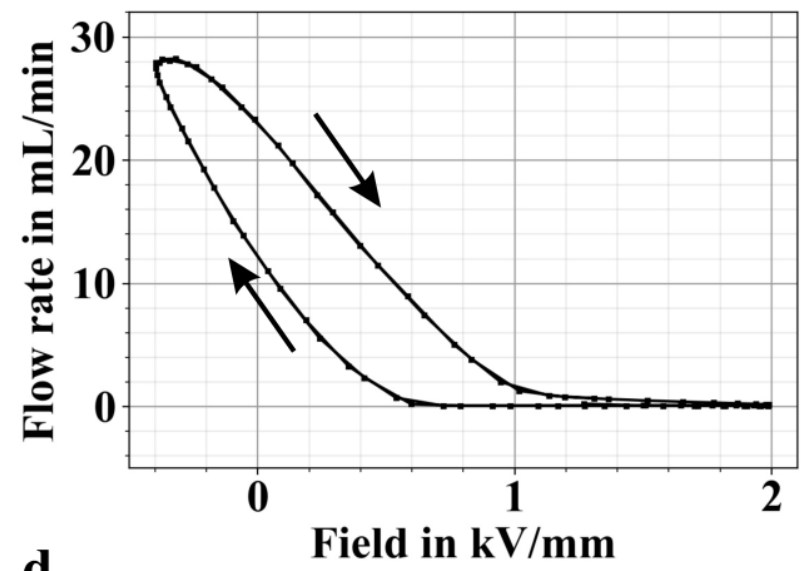

d

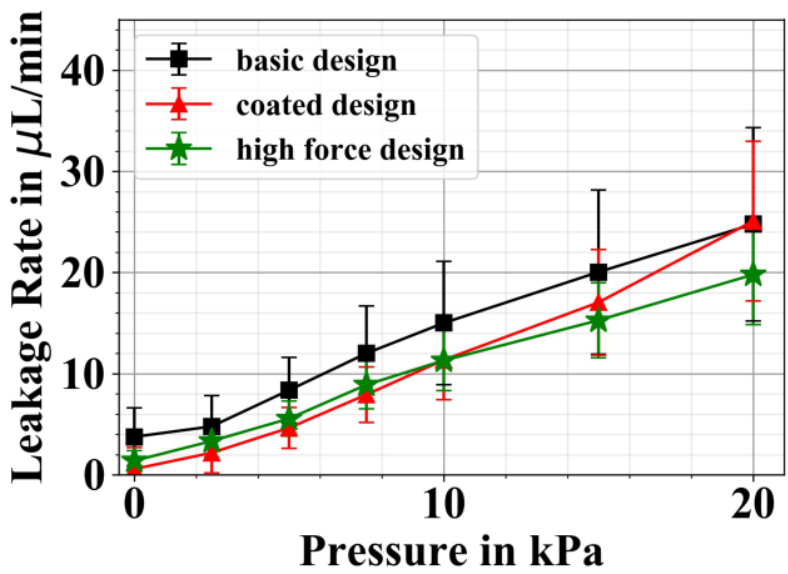

Figure 9. (a) Typical stroke measurement of the NO valve. At an applied field of approximately $1 \mathrm{kV} / \mathrm{mm}$, the actuator diaphragm sits on the valve seat, and downwards movement is inhibited. (b) Typical flow characteristic of an NO valve at an inlet pressure of $20 \mathrm{kPa}$ showing complete blockage of the fluidic path at approximately $1.6 \mathrm{kV} / \mathrm{mm}$ and a maximum open flow of $27 \mathrm{~mL} / \mathrm{min}$. (c) Average pressure-dependent flow rate in non-actuated state with an applied inlet pressure of up to $100 \mathrm{kPa}$. Error bars depict standard deviations. (d) Average pressure-dependent leakage with up to $20 \mathrm{kPa}$ inlet pressure. Error bars depict standard deviations.

Another important parameter of microvalves as fundamental components of microfluidic systems is their fluidic resistance in open state, which ideally should not impede the fluid flow. In order to investigate this parameter, we measure the flow rates through the NO valve in non-actuated state. As the inlet pressure increases, flow rates in NO state increase linearly for all microvalve designs, as shown in Figure 9c. Same as for active opening, a difference of the flow rate in NO state is observed when comparing the $0.2 \mathrm{~mm}$ piezoactuator valve variants $((122 \pm 9) \mathrm{mL} / \mathrm{min}$ for the basic design and $(119.1 \pm 8.4) \mathrm{mL} / \mathrm{min}$ with coating) to the high force design $((83.6 \pm 4.8) \mathrm{mL} / \mathrm{min})$. Again, this difference can be explained by the dissimilar stiffnesses of the valve diaphragms and the effect of the fluid pressure influencing the height of the valve chamber.

Microvalve leakage is presented in Figure 9d. The pressure-dependent leakage characteristic of $\mathrm{NO}$ valves of the basic design seem to exhibit the highest of all measured leakage behaviors; however, the differences are not statistically significant (Table 2).

While microvalves of the high force actuator variant exhibit the lowest leakage rates at the lowest standard deviations, better statistics are needed to assess the significance of the observed differences in order to evaluate the effect of an increased contact pressure. Since experimental leakage rates of the coated microvalves do not differ from the basic design, beneficial sealing properties as a result of the Parylene- $C$ coating cannot be derived to this 
date. However, the comparison of the measured leakage rates to former investigations of NO valves with soft sealing components [14] reveals that the microvalve variants presented here achieve similar leakage rates with significantly lower standard deviations. Therefore, the micromachined trenches are proven suitable for the fabrication of a microvalve with increased reliability with a view to sample-to-sample variation of the exhibited leakage rate due to higher manufacturing precision of the valve seat compared to microvalves comprising an O-ring soft sealing.

Comparison of the modeled values (see Figure 8) to experimentally collected data shows an overall overestimation of expected leakage rates, which, as already mentioned, constitutes an upper limit of the theoretically expected values. While leakages of both microvalve variants without coatings are overestimated approximately by a factor of 4 and 7 (high force design and basic design, respectively), the analytically calculated leakage rates of the coated microvalves differ from experimental data only by a factor of 1.5. Future work on analytical modeling of microvalve leakage rates should consequently involve a thorough investigation of contact pressure calculation accompanied by experimental investigation of the achieved forces of piezoceramics bonded to metal diaphragms.

\subsection{Fatigue Test}

A reliable and safe microfluidic device design is required in medical applications in order to minimize the risk of device failure. Hence, the stability of the microvalves performance is investigated by subjecting them to fatigue testing as described in Section 2.4.

Immediately after fatigue testing, we inspect the microvalve's piezoceramic actuator optically and by measurement of its electric capacitance in order to detect critical failure in the form of cracks. Valves with piezoceramic actuator failure are excluded from subsequent fluidic characterization. The changes in maximum open flow, NO flow, and leakage after fatigue testing compared to observed performances after manufacturing are summarized in Table 3.

Table 3. Results of $1 \times 10^{6}$ actuation fatigue test. Listed as piezoceramic actuator failures are observed material failures of the PZT in form of cracks. Change in fluidic performance is given for valves with functional piezoceramic actuator.

\begin{tabular}{cccccc}
\hline $\begin{array}{c}\text { Microvalve } \\
\text { Design Variants }\end{array}$ & $\begin{array}{c}\text { Fatigue Tested } \\
\text { Valves }\end{array}$ & $\begin{array}{c}\text { Piezoceramic } \\
\text { Actuator Failures }\end{array}$ & $\begin{array}{c}\text { Change of Max. } \\
\text { Open Flow, 20 kPa }\end{array}$ & $\begin{array}{c}\text { Change of } \\
\text { NO Flow, 100 kPa }\end{array}$ & $\begin{array}{c}\text { Change of } \\
\text { Leakage, 20 kPa }\end{array}$ \\
\hline Basic design & 5 & 3 & $(-6 \pm 3) \%$ & $(8 \pm 4) \%$ & $(123 \pm 62) \%$ \\
Coated design & 5 & 2 & $(-2 \pm 2) \%$ & $(0 \pm 11) \%$ & $(3 \pm 13) \%$ \\
High force design & 4 & 0 & $(6 \pm 4) \%$ & $(18 \pm 8) \%$ & $(14 \pm 15) \%$ \\
\hline
\end{tabular}

None of the 4 high force design valves show failure of the piezoceramic actuator, but a total of 5 out of the 10 tested microvalves with a $0.2 \mathrm{~mm}$ thick piezoceramic actuator experience material cracking of the piezoceramic (three basic design valves and two coated valves). To confirm increased robustness of the actuator with increased actuator thickness, further investigations with an increased number of samples are needed and are planned for future work.

Characterization of the active open flow rate shows only small changes (Table 3). The average change of $\mathrm{NO}$ flow rates at $100 \mathrm{kPa}$ is zero for microvalves with coating, and is increased slightly for the basic design; for the high force design valves, the flow rates increases notably. Microvalves with coating exhibit the lowest change in leakage after fatigue testing, whereas an increase of $14 \%$ of leakage rates is observed for high force design valves, and a strong increase of $123 \%$ is found for valves of the basic design.

Though standard deviations of the measured changes in leakage rates are high, a tendency of the stability of the tested designs can be deduced. Both design adaptions of the basic design, the coated as well as the high force design, show lower increase in leakage rates after the fatigue tests. The valve seat coated with Parylene-C seems to favor a good seal of the valve diaphragm to the seat even after fatigue. Comparing valves of the high force design to those of the basic design, the stiffer actuator capable of higher compression 
forces appears to exhibit higher robustness against fatigue testing regarding piezoceramic actuator failure as well as an increase in leakage rate. A larger number of samples for testing would be necessary for future studies to increase the statistical relevance of the results and further substantiate these findings.

\section{Conclusions}

This work provides a detailed investigation of NO microvalve development for medical applications, where many intricate requirements in flow performance, biocompatibility, hermetic sealing, and device reliability call for sophisticated solutions. We introduce a piezoelectric microvalve with multiple trenches serving as a valve seat and omit any movable soft sealing components in the valve chamber as an important step towards the reliable operation of the microfluidic device.

As alternatives for a soft sealing valve seat, we discuss different measures for optimized fluidic performance of the microvalve in closed state, provide insight into important influencing parameters of leakage rates, and propose three design variants of NO valves for fabrication and experimental characterization. Moreover, we derive an analytical model of the leakage rates and perform a dedicated FEA parameter study of the geometric dimensions of the trench design, enabling further $\mathrm{NO}$ valve optimization with a view to sealing performance as well as fluidic resistance.

The fabricated and tested microvalve variants with concentric trenches exhibit good leakage rates in closed state as low as $(19.8 \pm 4.9) \mu \mathrm{L} / \mathrm{min}$. This is comparable to former investigations of $\mathrm{NO}$ valves with soft sealing components but with better controllability of geometric parameters, hence, a low sample-to-sample variation, which is substantiated by small standard deviations of the measured leakage. We show that flow rates in open state are as high as $(30.1 \pm 3.4) \mathrm{mL} / \mathrm{min}$. Therefore, the presented sealing concept does not impede fluid flow, and malfunctions of the microvalve in open state are successfully avoided by the omittance of any additional movable components in the valve chamber. Fatigue testing of the microvalves reveals beneficial effects of Parylene- $C$ coating or increased piezoelectric actuator force on leakage rate stability and indicates increased piezoceramic material stability with increased thickness.

Due to its simplistic design, energy-efficient piezoelectric actuation, and beneficial material properties, the microvalve with multiple valve seat trenches lays a valuable basis for microfluidic medical device development. The comprehensive investigation of microvalve design provided in this work enables well-founded further development of the microfluidic device. Potential future work on the development of microvalves for medical applications may include optimization of the piezoceramic disk actuator design for increased contact pressure, extended fatigue testing, as well as fluidic characterizations at human body temperature.

Author Contributions: Conceptualization, C.P.D. and G.S.; methodology, C.P.D.; software, W.H., P.K.M. and C.P.D.; validation, C.P.D., S.T.G., P.K.M., W.H. and G.S.; formal analysis, C.P.D. and W.H.; investigation, C.P.D. and S.T.G.; resources, C.P.D., S.T.G. and W.H.; data curation, C.P.D., S.T.G. and W.H.; writing-original draft preparation, C.P.D., P.K.M. and W.H.; writing-review and editing, C.P.D. and G.S.; visualization, C.P.D. and W.H.; supervision, G.S.; project administration, C.P.D. All authors have read and agreed to the published version of the manuscript.

Funding: This research was funded by the Bavarian Ministry of Economic Affairs, Regional Development and Energy, within the Bavarian funding program for research and development "Electronic Systems" under the grant number ESB071/002.

Data Availability Statement: The experimental, analytical modeling, and simulation data that support the findings of this study are available in Fordatis-ResearchData Repository of FraunhoferGesellschaft with the identifier (https:/ / fordatis.fraunhofer.de/handle/fordatis/218 (accessed on 4 August 2021)). 
Acknowledgments: The authors would like to thank Christian Wald for funding acquisition as well as supervision of the research activity and Nivedha Surendran for assisting in our laboratory work. We are also thankful to Franz Selbmann from Fraunhofer ENAS for providing the Parylene-C deposition process parameters and topology data.

Conflicts of Interest: The authors declare no conflict of interest. The funders had no role in the design of the study; in the collection, analyses, or interpretation of data; in the writing of the manuscript, or in the decision to publish the results.

\section{Appendix A. Derivation of the Fluidic Resistance of a Stationary and Laminar Flow between Two Parallel Discs}

Appendix A.1. Governing Equations

Given two parallel discs with an inner radius $r_{0}$, an outer radius $r_{1}$ and a vertical distance $h$. We assume that the flow between these two plates is stationary and laminar. Additionally, we assume an incompressible, Newtonian fluid. Then the Navier-Stokes equations, representing conservation of momentum, are given as:

$$
\rho(\vec{v} \cdot \nabla) \vec{v}=-\nabla p+\mu \Delta \vec{v}
$$

and the continuity equation, representing conservation of mass, is given as:

$$
\nabla \cdot \vec{v}=0
$$

Here, $\rho=$ const. is the density and $\mu=$ const. is the viscosity of the fluid. The vector field $\vec{v}$ is the velocity field and $p$ the pressure. In cylindrical coordinates, the continuity equation for the velocity field $\vec{v}(r, \varphi, z)$ is given by:

$$
\frac{\partial v_{r}}{\partial r}+\frac{v_{r}}{r}+\frac{1}{r} \frac{\partial v_{\varphi}}{\partial \varphi}+\frac{\partial v_{z}}{\partial z}=0
$$

Due to the cylindrical symmetry, we assume that there is neither flow in azimuthal direction (swirl flow) nor in vertical direction resulting in $v_{\varphi}=v_{z}=0$. Additionally, also all derivatives with respect to $\varphi$ are zero. This results in the problem-adapted continuity equation:

$$
\frac{\partial v_{r}}{\partial r}+\frac{v_{r}}{r}=0
$$

The Navier-Stokes equation for the radial velocity component then becomes:

$$
\rho \cdot v_{r} \frac{\partial v_{r}}{\partial r}=-\frac{\partial p}{\partial r}+\mu\left(\frac{\partial^{2} v_{r}}{\partial r^{2}}+\frac{1}{r} \frac{\partial v_{r}}{\partial r}-\frac{v_{r}}{r^{2}}+\frac{\partial^{2} v_{r}}{\partial z^{2}}\right),
$$

and the remaining two equations become:

$$
\frac{\partial p}{\partial \varphi}=\frac{\partial p}{\partial z}=0
$$

Thus, the pressure varies only with the radius.

Differentiating the continuity Equation (A4) with respect to $r$ and substituting it into the Navier-Stokes equation yields:

$$
\rho \cdot v_{r} \frac{\partial v_{r}}{\partial r}=-\frac{\partial p}{\partial r}+\mu \frac{\partial^{2} v_{r}}{\partial z^{2}}
$$

\section{Appendix A.2. Dimensionless Formulation}

We can rewrite the above equation in a non-dimensional formulation, using characteristic values of the single entities. This enables a better quantitative and qualitative 
comparison between different geometrical variants. The radial velocity is then given as $v_{r}=v_{c} \cdot v_{r}^{*}$, the radius as $r=r_{0} \cdot r^{*}$, the pressure as $p=p_{0} \cdot p^{*}$ and the $z$-coordinate becomes $z=h \cdot z^{*}$, where $v_{c}$ denotes a characteristic value for the velocity, $r_{0}$ and $h$ denote the geometry parameters and $p_{0}$ is the input pressure.

The dimensionless equation is then given by:

$$
\frac{\rho v_{c} h}{\mu} \cdot v_{r}^{*} \frac{\partial v_{r}^{*}}{\partial r^{*}}=-\frac{p_{0} h}{v_{c} \mu} \cdot \frac{\partial p^{*}}{\partial r^{*}}+\frac{r_{0}}{h} \cdot \frac{\partial^{2} v_{r}^{*}}{\partial z^{* 2}} .
$$

We can identify the term $\frac{\rho v_{c} h}{\mu}$ as Reynold's number of the flow. Additionally defining $\alpha:=\frac{p_{0} h}{v_{c} \mu}$ and $\beta:=\frac{r_{0}}{h}$ dropping the asterisk, we finally arrive at:

$$
\operatorname{Re} \cdot v_{r} \frac{\partial v_{r}}{\partial r}=-\alpha \frac{\partial p}{\partial r}+\beta \frac{\partial^{2} v_{r}}{\partial z^{2}}
$$

Doing the same for the continuity equation and dropping the asterisks results in the same equation again, but then for dimensionless entities.

\section{Appendix A.3. Derivation of the Non-Linear Differential Equation for the Radial Velocity}

The continuity equation can be separated according to:

$$
\frac{\mathrm{d} v_{r}}{v_{r}}=-\frac{\mathrm{d} r}{r} .
$$

Solving this differential equation leads to $v_{r}=\frac{C(z)}{r}$, where the function $C(z)$ depends only on $z$. Inserting this equation into the Navier-Stokes equation yields:

$$
\operatorname{Re} \cdot \frac{C(z)}{r} \cdot\left(-\frac{C(z)}{r^{2}}\right)=-\alpha \frac{\partial p}{\partial r}+\beta \frac{C^{\prime \prime}(z)}{r}
$$

or respectively:

$$
\beta \frac{C^{\prime \prime}}{r}+\operatorname{Re} \cdot \frac{C^{2}}{r^{3}}=\alpha \frac{\partial p}{\partial r} .
$$

Integrating this equation with respect to $r$ within the interval $\left[1, \frac{r_{1}}{r_{0}}\right]$, i.e., the entire disc, we obtain the following non-linear equation for the radial component of the velocity:

$$
\beta \ln \frac{r_{1}}{r_{0}} \cdot C^{\prime \prime}+\left(\frac{1}{2}-\frac{r_{0}^{2}}{2 r_{1}^{2}}\right) \operatorname{Re} \cdot C^{2}=-\alpha \cdot\left(p_{0}-p_{1}\right) .
$$

\section{Appendix A.4. Linearization of the Differential Equation and Solution}

In the microvalve under consideration, the radii are much larger than the vertical gap between the discs. Furthermore, we expect the flow to be rather creeping than turbulent. For example, a setting with $r_{0}=1.1 \mathrm{~mm}, r_{1}=2.6 \mathrm{~mm}, h=25 \mu \mathrm{m}$ and $p_{0}=10 \mathrm{kPa}$, leads to a maximum Reynold's number of about $\operatorname{Re}=0.32$ in our simulations. The factor in front of the non-linear term then becomes about 0.13, while at the same time $\alpha \approx 295$ and $\beta=44$. Thus, we can neglect the non-linear term, and we obtain:

$$
C^{\prime \prime}(z)=-\frac{\gamma}{\ln \frac{r_{1}}{r_{0}}} \Delta p
$$

where the dimensionless constant $\gamma=\frac{p_{0} h^{2}}{\mu v_{c} r_{0}}$. For high Reynold's numbers, this simplification would not be appropriate, as then the turbulent flow contributes significantly to the fluidic resistance. 
Equation (A14) can be integrated twice over the height of the channel between the discs to obtain a polynomial of second order with two constants of integration. These constants are determined by applying no-slip boundary conditions at the discs. The coordinate system is oriented in such a way that the discs are symmetrically placed above, and below the $x y$-plane, i.e., they are located at $z= \pm \frac{1}{2}$ in our dimension-less formulation. We then obtain:

$$
C(z)=\frac{\gamma}{8 \ln \frac{r_{1}}{r_{0}}} \Delta p \cdot\left(1-4 z^{2}\right)
$$

and further for the dimension-less velocity (added asterisks to clearly distinguish between entities with and without dimensions):

$$
v_{r}^{*}\left(r^{*}, z^{*}\right)=\frac{p_{0} h^{2}}{8 \mu v_{\mathcal{c}} r_{0}} \frac{1}{\ln \frac{r_{1}}{r_{0}}} \frac{\Delta p^{*} \cdot\left(1-4 z^{* 2}\right)}{r^{*}},
$$

and finally for the radial velocity:

$$
v_{r}(r, z)=\frac{1}{8 \mu \ln \frac{r_{1}}{r_{0}}} \frac{\Delta p}{r}\left(h^{2}-4 z^{2}\right) .
$$

\section{Appendix A.5. Calculation of the Flowrate and the Fluidic Resistance}

The pressure-driven flow rate $\dot{q}$ between the two discs is obtained by integrating the radial velocity over the cylindrical surface with the height being the gap and the perimeter $r \cdot \mathrm{d} \varphi$. Exploiting the mirror symmetry around $z=0$ leads to:

$$
\dot{q}(r)=2 \int_{z=0}^{\frac{h}{2}} \int_{\varphi=0}^{2 \pi} v_{r}(r, z) r \mathrm{~d} \varphi \mathrm{d} z .
$$

This yields:

$$
\dot{q}=\frac{\pi h^{3}}{6 \mu \ln \frac{r_{1}}{r_{0}}} \Delta p
$$

Finally, the resistance for a radial, stationary, laminar flow between two parallel discs is given by:

$$
\frac{\Delta p}{\dot{q}}=\frac{6 \mu \ln \frac{r_{1}}{r_{0}}}{\pi h^{3}} .
$$

\section{Appendix B. Derivation of the Model of the Leakage Rates}

Appendix B.1. Persson's Theory of Contact Mechanics-Derivation of the Average Separation Height $u(p)$ of Two Contact Surfaces

Consider the frictionless contact between two elastic solids with surface profiles $h_{1}(x)$ and $h_{2}(x)$. The elastic contact problem of these solids is equivalent to the contact between a rigid solid (substrate) with surface profile $h(x)=h_{1}(x)+h_{2}(x)$ being in contact with an elastic solid (block) with a flat surface, whose Young's modulus $E$ and Poisson ratio $v$ are given by [35]:

$$
\frac{1-v^{2}}{E}=\frac{1-v_{1}^{2}}{E_{1}}+\frac{1-v_{2}^{2}}{E_{2}}
$$

where $E_{1}, E_{2}$ and $v_{1}, v_{2}$ are the Young's moduli and the Poisson ratios of the two solids, respectively. For the valves without Parylene coating, the effective Young's modulus for the steel-steel contact is of the same order of magnitude as the Young's modulus of stainless steel. For the valves with Parylene coating, the effective Young's modulus is significantly decreased since the Young's modulus of parylene is much smaller than the Young's modulus of steel $[26,27]$.

The contact between the two surfaces depends on the pressure that squeezes them together. When the applied contact pressure $\mathrm{p}$ is increased, the average surface separation 
$u$ is decreased, so the pressure $\mathrm{p}$ is again a function of $u: p=p(u)$. In order to setup an equation, we consider the energy balance $U_{e l}(u)$ stored in the deformed surface in the contact region and the mechanical work performed by the applied external pressure $p_{\text {contact }}$ [30]:

$$
\int_{u}^{\infty} d u^{\prime} A_{0} p\left(u^{\prime}\right)=U_{\mathrm{el}}(u)
$$

or equivalently:

$$
p(u)=-\frac{1}{A_{0}} \frac{d U_{\mathrm{el}}}{d u},
$$

where $A_{0}$ is the nominal contact area. For small pressures, it can be assumed that the elastic energy is linearly proportional to the load, i.e., $U_{\mathrm{el}}(u)=u_{0} A_{0} p(u)$ [30]. The characteristic length $u_{0}$ depends on the surface roughness but not on the contact pressure [30]. Thus, Equation (A23) can be simplified to:

$$
p(u)=-u_{0} \frac{d p}{d u}
$$

Or:

$$
p(u)=p_{c} e^{-u / u_{0}},
$$

which is in good agreement with experimental data [30]. Many surfaces of interest are self-affine fractals for $q_{0}<q<q_{1}$, where $q_{0}$ and $q_{1}$ are the lower and upper cutoff wave vectors. If a self-affine surface is magnified in a direction perpendicular to it, then the surface 'looks the same', i.e., the statistical properties of the surface are invariant under scale transformation. The surface roughness of a self-affine fractal can be described by a fractal geometry $D_{f}$ with $2<D_{f}<3$, whereby a value of 2 corresponds to a perfectly smooth surface and the limiting case of $D_{f}=3$ is equivalent to a three-dimensional body. For most surfaces, the fractal dimension is smaller than 2.3 [36]. Persson also derived expressions for $p_{c}$ and $u_{0}$ for a self-affine fractal surface [30]. The final simplified expressions for the contact pressure $p(u)$ and the average surface separation $u(p)$ are given by:

$$
p(u)=\beta \in q_{0} h_{r m s} E^{*} e^{-\alpha u / \gamma h_{r m s}}
$$

And:

$$
u(p)=\gamma \alpha^{-1} h_{r m s} \log \left(\beta \epsilon q_{0} h_{r m s} \frac{E^{*}}{p}\right) .
$$

In the equations above, $q_{0}$ is the upper cutoff wavevector in the fractal analysis, $h_{r m s}$ is the root-mean-square value of the surface roughness, $E^{*}=E /\left(1-v^{2}\right)$ and $\epsilon=0.7493$ [30]. The constant $\gamma<1$ (but of order unity) takes into account that the contact is not perfect, and the elastic energy stored in the contact region is less than the average elastic energy [30]. For simplification, it is set to $\gamma=1$ in the following calculations. $\alpha$ and $\beta$ are factors in the context of the theory of contact mechanics and are functions of the fractal dimension and the ratio $q_{1} / q_{0}$. In the case of $D_{f}<2.3$, both constants are nearly independent of the ratio $q_{1} / q_{0}$ and are approximately given by $\alpha \approx 1$ and $\beta \approx 0.5$ [30]. According to the Equation (A27), the average surface separation and, hence, the leakage path in the valves with parylene coating will be decreased since the value of $E^{*}$ is much smaller, and the leakage rates are expected to be smaller than for the valves without Parylene.

\section{Appendix B.2. Calculation of Contact Pressure $p_{\text {contact }}$}

In a non-actuated state, the valve is open, and the fluid can pass through. Applying a positive voltage to the piezoceramic causes a deflection of the actuator towards the valve seat, whereas a negative voltage actively opens the valve and decreases its fluidic resistance. The stroke volume, which is the volume displaced by the piezoelectric actuator, depends 
approximately linearly on the electrical excitation and the applied pressure difference at the diaphragm [31]:

$$
V\left(p, E_{z}\right)=C_{E} \cdot\left(E_{z}-E_{0}\right)+C_{p} \cdot\left(p-p_{0}\right) .
$$

Here, $E_{z}-E_{0}$ is the electric field applied to the piezoceramic with $E_{0}=0, p_{0}$ is the atmospheric pressure and $C_{E}$ and $C_{p}$ are the volumetrical-electrical coupling coefficient and the fluidic capacitance, respectively. In [31], both coefficients are calculated for a circular piezoceramic with radius $R_{1}$, which is bonded to a circular diaphragm with radius $R_{2}$ clamped at $r=R_{2}$. The expressions depend on the thicknesses of the piezoceramic and the diaphragm, their elastic moduli, the Poisson ratios of the piezoceramic and the diaphragm, and the piezoelectric coefficient $d_{31}$, that quantifies the stretching of the piezoceramic in the $x_{1}$-direction for an electric field applied in the $x_{3}$-direction.

To ensure blocking of the fluid, the force of the actuator must be larger than the force exerted to the diaphragm by the pressure of the fluid. The threshold pressure that is necessary to close the channel is called the blocking pressure. It depends on the properties of the piezoceramic material and the difference $\Delta U$ between the maximal actuation voltage and the minimum actuation voltage. The blocking pressure is defined as the pressure, where the stroke volume is zero and can be derived according to [31]:

$$
p_{\text {block }}=-\frac{C_{E}^{*}}{C_{p}}\left(U_{+}-U_{-}\right)+p_{0}
$$

In the equation above, $C_{E}^{*}=C_{E} / d_{P}$ with $d_{P}$ is the thickness of the piezoceramic layer, and $U_{+}$and $U_{-}$are the electric voltages corresponding to the minimal and maximal position of the diaphragm. The contact pressure derived from contact mechanics is related to the blocking pressure. Since the blocking pressure is defined as the actuator force on the diaphragm, but the contact area is smaller than its total surface, the contact pressure is given by the blocking pressure multiplied by the ratio of these two areas. Therefore, the expression for the contact pressure is given by:

$$
p_{\text {contact }}=\frac{A_{\text {diaphragm }}}{A_{\text {contact }}} p_{\text {block }}
$$

with $A_{\text {diaphragm }} / A_{\text {contact }} \approx 1.06$. This expression can be inserted into Equation (5) to calculate the average surface separation, which is the key parameter for estimating leakage flow rates in metal seals.

\section{References}

1. Moreno, M.; Aracil, C.; Quero, J.M. High-integrated microvalve for lab-on-chip biomedical applications. In 2008 IEEE Biomedical Circuits and Systems Conference, Baltimore, MD, USA, 20-22 November 2008; IEEE: New York, NY, USA, 2009; pp. 313-316. ISBN 1424428785.

2. Qian, J.-Y.; Hou, C.-W.; Li, X.-J.; Jin, Z.-J. Actuation Mechanism of Microvalves: A Review. Micromachines 2020, 11, 172. [CrossRef] [PubMed]

3. Oh, K.; Ahn, C. A Review of Microvalves. J. Micromech. Microeng. 2006, 16, 13-39. [CrossRef]

4. Chappel, E. A Review of Passive Constant Flow Regulators for Microfluidic Applications. Appl. Sci. 2020, 10, 8858. [CrossRef]

5. Fazal, I.; Elwenspoek, M.C. Design and analysis of a high pressure piezoelectric actuated microvalve. J. Micromech. Microeng. 2007, 17, 2366-2379. [CrossRef]

6. $\quad$ Park, J.M.; Taylor, R.P.; Evans, A.T.; Brosten, T.R.; Nellis, G.F.; Klein, S.A.; Feller, J.R.; Salerno, L.; Gianchandani, Y.B. A piezoelectric microvalve for cryogenic applications. J. Micromech. Microeng. 2008, 18, 15023. [CrossRef]

7. Megnin, C.; Barth, J.; Kohl, M. A bistable SMA microvalve for 3/2-way control. Sens. Actuators A Phys. 2012, 188, $285-291$. [CrossRef]

8. Kohl, M.; Dittmann, D.; Quandt, E.; Winzek, B. Thin film shape memory microvalves with adjustable operation temperature. Sens. Actuators A Phys. 2000, 83, 214-219. [CrossRef]

9. Kolari, K.; Havia, T.; Stuns, I.; Hjort, K. Flow restrictor silicon membrane microvalve actuated by optically controlled paraffin phase transition. J. Micromech. Microeng. 2014, 24, 84003. [CrossRef]

10. Yang, B.; Lin, Q. A latchable microvalve using phase change of paraffin wax. Sens. Actuators A Phys. 2007, 134, 194-200. [CrossRef] 
11. Nafea, M.; Nawabjan, A.; Mohamed Ali, M.S. A wirelessly-controlled piezoelectric microvalve for regulated drug delivery. Sens. Actuators A Phys. 2018, 279, 191-203. [CrossRef]

12. Evans, A.T.; Park, J.M.; Chiravuri, S.; Gianchandani, Y.B. A low power, microvalve regulated architecture for drug delivery systems. Biomed. Microdevices 2010, 12, 159-168. [CrossRef]

13. Im, S.B.; Uddin, M.J.; Jin, G.J.; Shim, J.S. A disposable on-chip microvalve and pump for programmable microfluidics. Lab Chip 2018, 18, 1310-1319. [CrossRef]

14. Bußmann, A.B.; Durasiewicz, C.P.; Kibler, S.H.A.; Wald, C.K. Piezoelectric titanium based microfluidic pump and valves for implantable medical applications. Sens. Actuators A Phys. 2021, 323, 112649. [CrossRef]

15. Cheng, C.-H.; Chao, C.; Cheung, Y.-N.; Xiao, L.; Yang, M.; Leung, W. A transcutaneous controlled magnetic microvalve based on iron-powder filled PDMS for implantable drug delivery systems. In 2008 3rd IEEE International Conference on Nano/Micro Engineered and Molecular Systems, Sanya, China, 6-9 January 2008; IEEE: New York, NY, USA, 2008; Volume 012008, pp. 1160-1163. ISBN 978-1-4244-1907-4.

16. Titano, J.J.; Fischman, A.M.; Cherian, A.; Tully, M.; Stein, L.L.; Jacobs, L.; Rubin, R.A.; Bosley, M.; Citron, S.; Joelson, D.W.; et al. End-hole Versus Microvalve Infusion Catheters in Patients Undergoing Drug-Eluting Microspheres-TACE for Solitary Hepatocellular Carcinoma Tumors: A Retrospective Analysis. Cardiovasc. Interv. Radiol. 2019, 42, 560-568. [CrossRef] [PubMed]

17. Oh, J.; Kim, G.; Kralick, F.; Noh, H. Design and Fabrication of a PDMS/Parylene Microvalve for the Treatment of Hydrocephalus. J. Microelectromech. Syst. 2011, 20, 811-818. [CrossRef]

18. Galanopoulos, S.; Chatzidai, N.; Melissinaki, V.; Selimis, A.; Schizas, C.; Farsari, M.; Karalekas, D. Design, Fabrication and Computational Characterization of a 3D Micro-Valve Built by Multi-Photon Polymerization. Micromachines 2014, 5, 505-514. [CrossRef]

19. Schizas, C.; Melissinaki, V.; Gaidukeviciute, A.; Reinhardt, C.; Ohrt, C.; Dedoussis, V.; Chichkov, B.N.; Fotakis, C.; Farsari, M.; Karalekas, D. On the design and fabrication by two-photon polymerization of a readily assembled micro-valve. Int. J. Adv. Manuf. Technol. 2010, 48, 435-441. [CrossRef]

20. Chen, P.-J.; Rodger, D.C.; Humayun, M.S.; Tai, Y.-C. Floating-disk parylene microvalve for self-regulating biomedical flow controls. In 2008 IEEE 21st International Conference on Micro Electro Mechanical Systems, Tucson, AZ, USA, 13-17 January 2008; IEEE: New York, NY, USA, 2008; Volume 012008, pp. 575-578. ISBN 978-1-4244-1792-6.

21. European Parliament and of the Council. Regulation (EU) 2017/745 of the European Parliament and of the Council of 5 April 2017 on Medical Devices, Amending Directive 2001/83/EC, Regulation (EC) No 178/2002 and Regulation (EC) No 1223/2009 and repealing Council Directives 90/385/EEC and 93/42/EEC. Available online: http:/ / data.europa.eu/eli/reg/2017/745/oj (accessed on 4 August 2021).

22. Lv, J.; Jiang, Y.; Zhang, D.; Zhao, Y.; Sun, X. Characterization on the fatigue performance of a piezoelectric microvalve with a microfabricated silicon valve seat. J. Micromech. Microeng. 2014, 24, 015013. [CrossRef]

23. Yang, E.-H.; Lee, C.; Mueller, J.; George, T. Leak-Tight Piezoelectric Microvalve for High-Pressure Gas Micropropulsion. J. Microelectromech. Syst. 2004, 13, 799-807. [CrossRef]

24. Zhang, D.; Lv, J.; Jiang, Y.; Chen, H.; Fu, J. A piezoelectric microvalve with a flexure-hinged driving frame and microfabricated silicon sealing pair. Mechatronics 2014, 24, 511-518. [CrossRef]

25. Cieślik, M.; Kot, M.; Reczyński, W.; Engvall, K.; Rakowski, W.; Kotarba, A. Parylene coatings on stainless steel 316L surface for medical applications-Mechanical and protective properties. Mater. Sci. Eng. C Mater. Biol. Appl. 2012, 32, 31-35. [CrossRef]

26. Chen, Z.; Gandhi, U.; Lee, J.; Wagoner, R.H. Variation and consistency of Young's modulus in steel. J. Mater. Process. Technol. 2016, 227, 227-243. [CrossRef]

27. Harder, T.A.; Yao, T.-J.; He, Q.; Shih, C.-Y.; Tai, Y.-C. Residual Stress in Thin-Film Parylene-C. Technical Digest. MEMS 2002 IEEE International Conference. In Proceedings of the Fifteenth IEEE International Conference on Micro Electro Mechanical Systems (Cat. No.02CH37266), Las Vegas, NV, USA, 24 January 2003; pp. 435-438. [CrossRef]

28. Geanta, V.; Voiculescu, I.; Stefanoiu, R.; Rusu, E.R. Stainless Steels with Biocompatible Properties for Medical Devices. Key Eng. Mater. 2013, 583, 9-15. [CrossRef]

29. Fortin, J.B.; Lu, T.-M. Deposition Kinetics for Polymerization via the Gorham Route. In Chemical Vapor Deposition Polymerization: The Growth and Properties of Parylene Thin Films; Fortin, J.B., Lu, T.-M., Eds.; Springer US: Boston, MA, USA, 2004 ; pp. 41-55. ISBN 978-1-4757-3901-5.

30. Persson, B.N.J. Relation between interfacial separation and load: A general theory of contact mechanics. Phys. Rev. Lett. 2007, 99, 125502. [CrossRef] [PubMed]

31. Herz, M.; Horsch, D.; Wachutka, G.; Lueth, T.C.; Richter, M. Design of ideal circular bending actuators for high performance micropumps. Sens. Actuators A Phys. 2010, 163, 231-239. [CrossRef]

32. Gad-el-Hak, M. The MEMS Handbook; CRC Press: Boca Raton, FL, USA, 2002; ISBN 9780849300776.

33. Squires, T.M.; Quake, S.R. Microfluidics: Fluid physics at the nanoliter scale. Rev. Mod. Phys. 2005, 77, 977-1026. [CrossRef]

34. Bruus, H. Theoretical Microfluidics; Oxford University Press: Oxford, UK, 2008.

35. Yang, C.; Persson, B.N.J. Contact mechanics: Contact area and interfacial separation from small contact to full contact. J. Phys. Condens. Matter 2008, 20, 215214. [CrossRef]

36. Persson, B.N.J. On the Fractal Dimension of Rough Surfaces. Tribol. Lett. 2014, 54, 99-106. [CrossRef] 